\title{
Research Article \\ Discoloration and Degradation of Bamboo under Ultraviolet Radiation
}

\author{
Haixia Yu $\mathbb{D},{ }^{1}$ Shengliang He, ${ }^{2}$ Wenfu Zhang, ${ }^{1}$ Mengyao Zhan, ${ }^{1}$ Xiaowei Zhuang, \\ Jin Wang $\left(1,{ }^{1}\right.$ and Wenji Yu $\mathbb{1}^{3}$ \\ ${ }^{1}$ Zhejiang Academy of Forestry (Zhejiang Provincial Key Laboratory of Biological and Chemical Utilization of Forest Resources), \\ 399\# Liuhe Road, Xihu District, Hangzhou, Zhejiang 310023, China \\ ${ }^{2}$ Zhejiang Jiahe Bamboo Technology Co., Ltd, Longbanshan, Industrial Area, Suichang, Zhejiang 323300, China \\ ${ }^{3}$ Chinese Academy of Forestry, 1\# Dongxiaofu, Xiangshan Road, Haidian Area, Beijing, China
}

Correspondence should be addressed to Jin Wang; whuwj@sina.com and Wenji Yu; chinayuwj@126.com

Received 3 June 2021; Revised 28 June 2021; Accepted 25 July 2021; Published 19 August 2021

Academic Editor: Likun Gao

Copyright (c) 2021 Haixia Yu et al. This is an open access article distributed under the Creative Commons Attribution License, which permits unrestricted use, distribution, and reproduction in any medium, provided the original work is properly cited.

Light is one of the most adverse factors for bamboo deterioration and causes surface degradation and discoloration. The study was carried out to initiate efficient and effective photodiscoloration to modify and enrich bamboo colors that may be applied to bamboo dyeing. Different types of bamboo samples commonly used in the industry were studied experimentally under two types of ultraviolet (UV) light. Effects of light sources, radiation time, and distances on discoloration and discoloration mechanism were systematically studied. For both UV 313 and high-pressure mercury light, the bamboo surface turned red-yellow, and color parameters including $\Delta E, \Delta a, \Delta b$, and $C$ rapidly increased first and then stabilized for long time, while $\Delta L$ showed a similar trend, except for the final decrease. Compared with UV 313, high-pressure mercury lamp light was highly efficient and took less time to induce discoloration. Heat treatments darkened the bamboo color and slowed down photodiscoloration, and the higher temperature led to more photostability. The color change of bamboo scrimber under UV radiation was less and slower than that of untreated bamboo due to high density and heat treatment, and the dark carbonized scrimber changed less than that of the light carbonized scrimber. Relatively high contents of isovanillin, syringaldehyde, $\beta$-hydroxypropiovanillone, $\mathrm{p}$-hydroxybenzaldehyde, and syringic acid were identified by GC-MS, and syringaldehyde, 2,6-dimethylbenzoquinone, and 3-hydroxy-4-methoxybenzoic acid were identified by HPLC-MS from a bamboo discoloration layer after high-pressure mercury lamp radiation. These products all contained a conjugated double bond and were conjectured to be degraded from lignin or aromatic extracts. Particularly, 2,6dimethylbenzoquinone which contained a cyclohexenedione structure without benzene rings, was more chemically stable than other conjugated double bonds with benzene rings, and was supposed to be the final product (chromogenic group) during bamboo photodegradation. Untreated or light-colored bamboo under high-energy UV light initiated highly efficient and effective photodiscoloration, and UV light is recommended for being applied to industrial bamboo dyeing. Compared with traditional chemical dyeing, the photoinduced dyeing method has no chemical addition and is easy to operate and environmental-friendly.

\section{Introduction}

Color, as one important visual property of wooden materials, is mainly determined by the reflection spectrum that comes from selective light absorption of chemical components [1]. Cellulose and hemicellulose are both saturated organic polymers with single bonds and do not absorb wavelength from 200 to $1000 \mathrm{~nm}$, which accounts for their white color [2]. In contrast, lignin contains many unsaturated dou- ble bonds, such as carbonyl group and vinyl group. The conjugated system links with the benzene ring to form the chromogenic group [2]. Aromatic extracts such as phenols also contain conjugated double bonds and strongly absorb visible light. Lignin and extracts are the main sources of wood color [3]. Unsaturated double bonds are very sensitive to light, especially ultraviolet (UV) light. The existing studies on photoinduced discoloration are focused on wood [4-6], but rarely on bamboo. As a highly lignified grass, bamboo 
has a chemical composition (e.g., lignin and extracts) different from that of wood. Bamboo lignin contains 5\%-10\% pcoumaric acid ester bonds in addition to guaiacyl, syringyl, and p-hydroxyphenyl lignin monomers [7]. Bamboo is also rich in phenolic acids $(0.3270-1.6352 \mathrm{ug} / \mathrm{mL}$ in cell walls), such as hydroxycinnamic acids, gallic acid, ferulic acid, cinnamic acid, and caffeic acid, which are precursors of lignin synthesis in grass cell walls [8]. Thus, further research is needed to better understand bamboo photodegradation and discoloration. During outdoor application, sunlight is one of the most adverse factors for wooden material degradation in addition to biodegradation [9] and leads to surface degradation and discoloration. Light aging is a surface phenomenon without affecting mechanical strength. Monitoring of free radicals by electron spin resonance spectroscopy (ESR) shows that UV light penetrates only $75 \mu \mathrm{m}$ in wood, but visible light can reach $200 \mu \mathrm{m}$ [4]. Under radiation by light, bamboo surface layers rapidly discolor to form a protective layer on the surface, so may photodiscoloration be used to modify and enrich bamboo surface color?

In this paper, photodiscoloration of different bamboo materials was systematically analyzed with 2 types of UV light source, aimed at initiating efficient, effective, and controllable photodiscoloration that may be applied to bamboo dyeing. In the experiments, bamboo was innovatively dyed with the chromogenic group initiated by UV light. Compared with traditional bamboo dyeing [10], the new method has no chemical addition and is easy to operate and environmentalfriendly.

\section{Materials and Methods}

2.1. Specimen Preparation. Four-year-old Moso bamboo (Phyllostachys pubescens Mazel) culms were cut from a bamboo genus garden of the Zhejiang Academy of Forestry. The $1 \mathrm{~m}$ long culms were sawed at breast height $(\sim 1.3 \mathrm{~m}$ from base) and then divided to $20 \mathrm{~mm}$ wide strips. Bamboo green was removed and then planed to the thickness of $\sim 1.2 \mathrm{~mm}$.

2.2. UV Radiation. Bamboo specimens were exposed to highpressure mercury light (31\% UV-A, 24\% UV-B, and 25\% UV-C) and UV $313\left(0.68 \mathrm{~W} / \mathrm{m}^{2}\right.$, at $310 \mathrm{~nm}$ and 290 to $315 \mathrm{~nm}$ ) with a cooling fan during working. The total electric power of the high-pressure mercury light was $1000 \mathrm{~W}$. Distance between each specimen and the light source as well as radiation time was set according to the type of specimens. Powder was scraped from the top surface of bamboo specimens with a sharp blade after UV radiation for gas chromatography-mass spectrometry (GC-MS), highperformance liquid chromatography (HPLC-MS), and Fourier transform infrared spectrometry (FTIR).

2.3. Color Measurement. Surface color was monitored by using a CM-3600d colorimeter (Datacolor, Japan) at 360$740 \mathrm{~nm}$ with a measuring head of $8 \mathrm{~mm}$ in diameter, CIE Illuminant D65, and observation angle of $10^{\circ}$. Three parallel specimens were set for each test. The two ends and the center of each specimen were marked by circles as the color measuring areas, and the spectrum was the mean of nine measurements. Color changes were analyzed by using a CIELAB system and characterized by $L$ (lightness, 100 for pure white, 0 for total black), $a$ ( $+a$ for red, $-a$ for green), and $b$ ( $+b$ for yellow, $-b$ for blue). The total color change $(\Delta E)$ and chromer ( $C$ color saturation) were calculated from $\Delta L, \Delta a$, and $\Delta b$ as follows:

$$
\begin{aligned}
& \Delta E=\sqrt{(\Delta a)^{2}+(\Delta b)^{2}+(\Delta L)^{2}}, \\
& C=\sqrt{(\Delta a)^{2}+(\Delta b)^{2}} .
\end{aligned}
$$

The reflectance spectrum was converted to the $K-M$ function [3] as follows:

$$
F\left(\gamma_{\lambda}\right)=\frac{K}{S}=\frac{\left(1-\gamma_{\lambda}\right)}{2 \gamma_{\lambda}} \gamma_{\lambda}=\frac{\gamma_{(\text {sample })}}{\gamma_{(\text {standard })}}
$$

where $K$ and $S$ are the absorption and scattering coefficients, respectively, and $r$ is the ratio of sample reflectance $\left(\gamma_{(\text {sample })}\right)$ to the reflectance of Whatman cellulose paper no. 42 with a defined porosity $\left(\gamma_{(\text {standard })}\right)$.

2.4. HPLC-MS Analysis. The Ultimate 3000 UPLC HPLC-MS instrument was operated at $254 \mathrm{~nm}$ (190-800 nm full scan). Mobile phase A was $1 \%$ formic acid aqueous solution, and mobile phase $\mathrm{B}$ was $0.1 \%$ acetonitrile at a flow rate of $0.25 \mathrm{~mL} / \mathrm{min}$. Gradient elution program was $t=0-6-20$ $-24-24.1-34$ and $A \%=2-10-90-90-2-2$.

2.5. GC-MS Analysis. The Agilent 7890 A GC-MS system was equipped with a $0.25 \mu \mathrm{m}$ RTX-5MS column $(30 \mathrm{~m} \times 0.25 \mathrm{~mm}$ $\times 0.25 \mu \mathrm{m})$. The injector was maintained at $270^{\circ} \mathrm{C}$. The column temperature was programmed as follows: $50^{\circ} \mathrm{C}$ $(1 \mathrm{~min}), 5^{\circ} \mathrm{C} / \mathrm{min}$ to $240^{\circ} \mathrm{C}(1 \mathrm{~min})$, and $10^{\circ} \mathrm{C} / \mathrm{min}$ to $280^{\circ} \mathrm{C}$ (10 min). The splitless injection mode was used with a split ratio of $30: 1$, and $1 \mathrm{~mL}$ of each sample was introduced. Full-scan MS was conducted at EM voltage of $1306 \mathrm{~V}, \mathrm{MS}$ source of $230^{\circ} \mathrm{C}$, and MS quad of $150^{\circ} \mathrm{C}$.

2.6. FTIR Analysis. Specimens (20 mg, from Section 2.1) were mixed with $3 \mathrm{~g}$ of $\mathrm{KBr}$ (spectroscopic grade) at the mixing ratio of $1: 150$. Spectra were recorded with an FTIR instrument (Nicolet, iS10, USA) with $4 \mathrm{~cm}^{-1}$ resolution, 64 scan times, and $400-4000 \mathrm{~cm}^{-1}$ spectral range. Special attention was given to absorption peaks from 800 to $1800 \mathrm{~cm}^{-1}$.

2.7. Thermal Treatment and UV Radiation. (a) Saturated steam thermal treatment (SS): bamboo specimens were put in a sealed tank and ventilated with saturated steam at the pressure of $0.39 \mathrm{MPa}$ for $2 \mathrm{~h}$. Then, the pressure was released and the specimens were removed. (b) High-temperature air thermal treatment (HTA): specimens were put in an oven at $180^{\circ} \mathrm{C}$ and removed after $2 \mathrm{~h}$. (c) Hot water thermal treatment $(\mathrm{HW})$ : specimens were put in a water bath at $80^{\circ} \mathrm{C}$ and removed after $2 \mathrm{~h}$. After heat treatments, the specimens were stored in a room at $20^{\circ} \mathrm{C}$ and $65 \%$ relative humidity $(\mathrm{RH})$ for 2 weeks and then exposed to UV light (UV 313 or highpressure mercury light) 


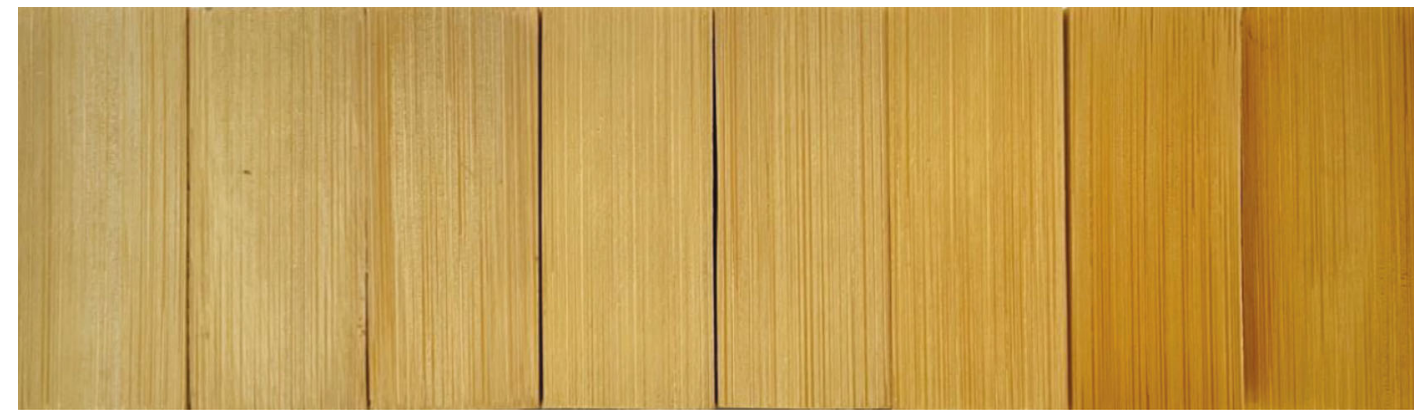

Figure 1: Effects of distance on bamboo color (from left to right: control and 30, 20, 15, 12.5, 10, 7.5, and $5 \mathrm{~cm}$ ).
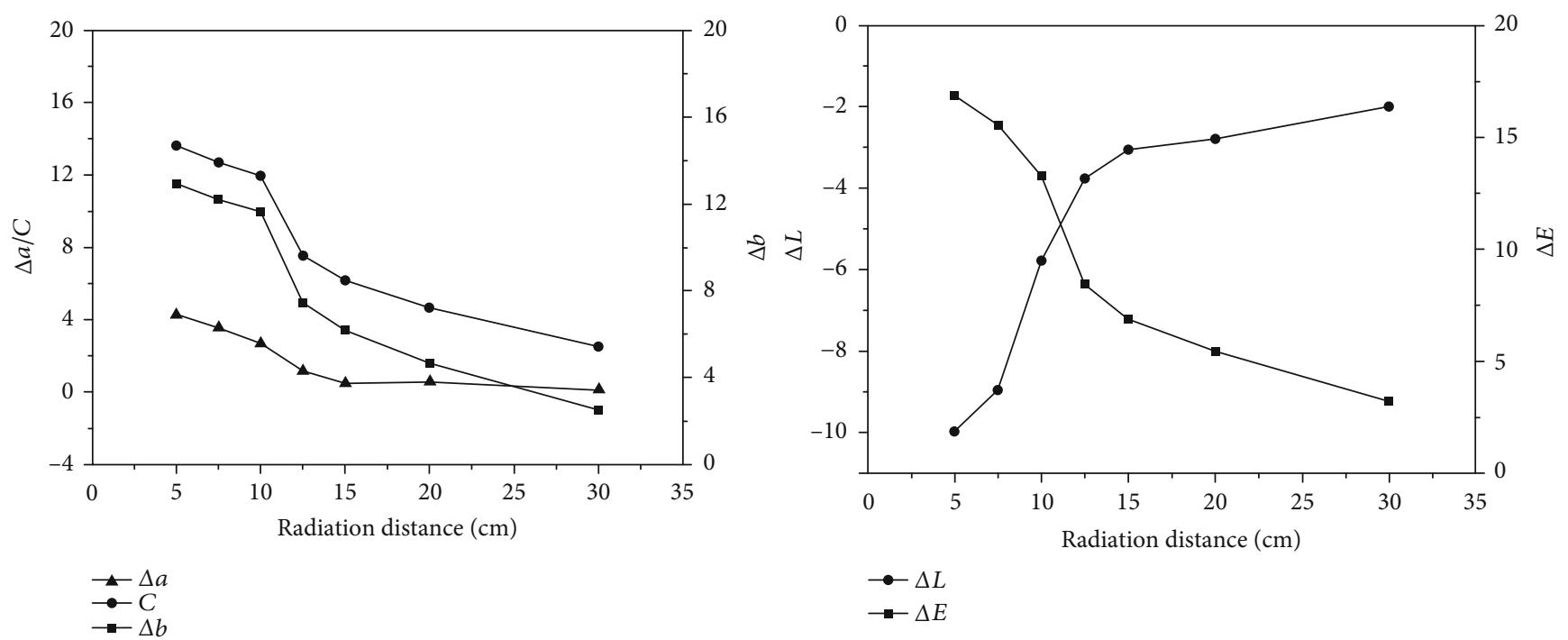

Figure 2: Effects of distance on $\Delta E, \Delta L, \Delta a, \Delta b$, and $C$ of bamboo (from left to right: $5,7.5,10,15,20$, and $30 \mathrm{~cm}$ ).

\section{Results and Discussion}

\subsection{Effect of UV Radiation Distance on Bamboo Surface} Color. Bamboo specimens (from Section 2.1) were studied by radiating with high-pressure mercury light for 4 minutes and set at different distances to the light source (Figure 1). The experiments were carried out in a room with constant temperature of $23^{\circ} \mathrm{C}$ and humidity of $65 \% \mathrm{RH}$, and a cooling fan was blowing the surfaces of the specimens at high-speed rotation. Clearly, surface color became increasingly yellow and turned to a warm color tone. Bamboo was apparently discolored at $10 \mathrm{~cm}$ distance from the light source. When the distance was $7.5 \mathrm{~cm}$ or near, bamboo surfaces became more colored and burned or carbonized for the high energy of the mercury light.

$\Delta E, \Delta a$, and $\Delta b$ increased when the distance narrowed and rapidly increased at $12.5 \mathrm{~cm}$ or nearer (Figure 2). $\Delta L$ showed a similar trend but decreased finally. The increase in $\Delta a$ and $\Delta b$ indicated that the bamboo surface changed to red-yellow after aging, while color saturation $(C)$ increased. The ideal radiation distance for high-pressure mercury light on bamboo was $10 \mathrm{~cm}$.

3.2. Effect of UV Radiation Time on Bamboo Surface Color. Effect of radiation time on bamboo discoloration was studied with a $10 \mathrm{~cm}$ distance between each specimen and the highpressure mercury light. The bamboo surface was yellowing and dark with the prolonging of time (Figure 3). Bamboo showed slight discolor from 2 to $3 \mathrm{~min}$, apparent discoloration occurred at $4 \mathrm{~min}$, and then color gradually increased with the extension of time.

$\Delta E, \Delta a, \Delta b$, and $C$ increased as the aging time extended (Figure 4). $\Delta E, \Delta a, \Delta b$, and $C$ rapidly increased at the beginning $4 \mathrm{~min}$ and then slowed down. $\Delta L$ showed a similar trend but decreased at last. Color parameter changes showed the similar trend as visual appearance in Figure 2.

Radiation time of the high-pressure mercury light was prolonged to $20 \mathrm{~h}$ with the minimum interval of $0.5 \mathrm{~h}$ (Figure 5). Bamboo was further yellowing when aging extended, and the changes of color parameters gradually slowed down after $6 \mathrm{~h}$ (Figure 6).

3.3. Reflectance Spectra of UV-Radiated Bamboo. Spectral reflectance is closely related to light and color, as the reflectance rates of white and black are close to $100 \%$ and $0 \%$, respectively. A narrower and sharper reflection peak means that molecules are more selective to different wavelengths of visible light absorption and the object is brighter. On the contrary, a wider and flatter reflection peak indicates that the color of the object is darker. After $20 \mathrm{~h}$ of radiation by 


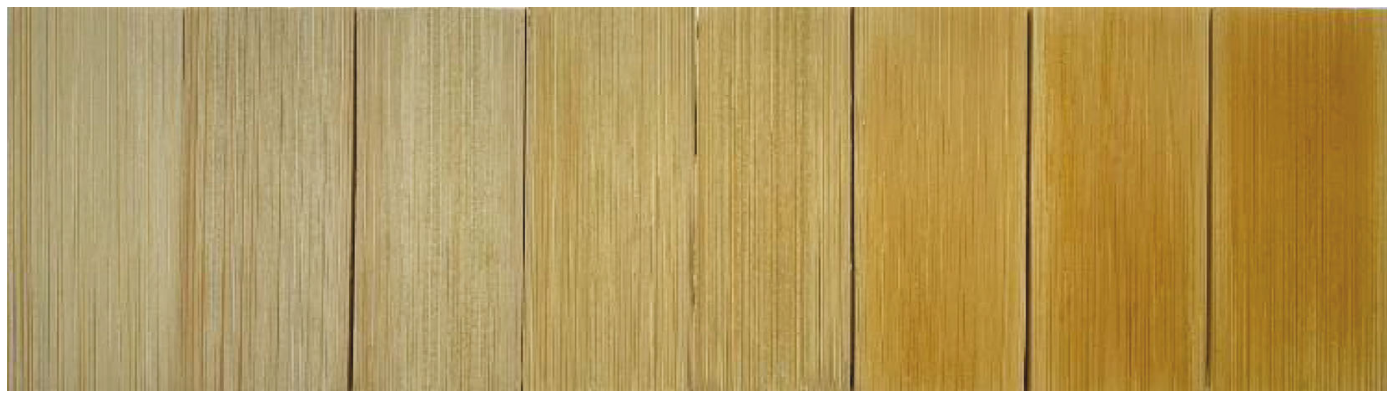

Figure 3: Effects of radiation time on bamboo color (10 cm distance, from left to right: control and $0.5,1,2,3,4,6$, and $8 \mathrm{~min})$.
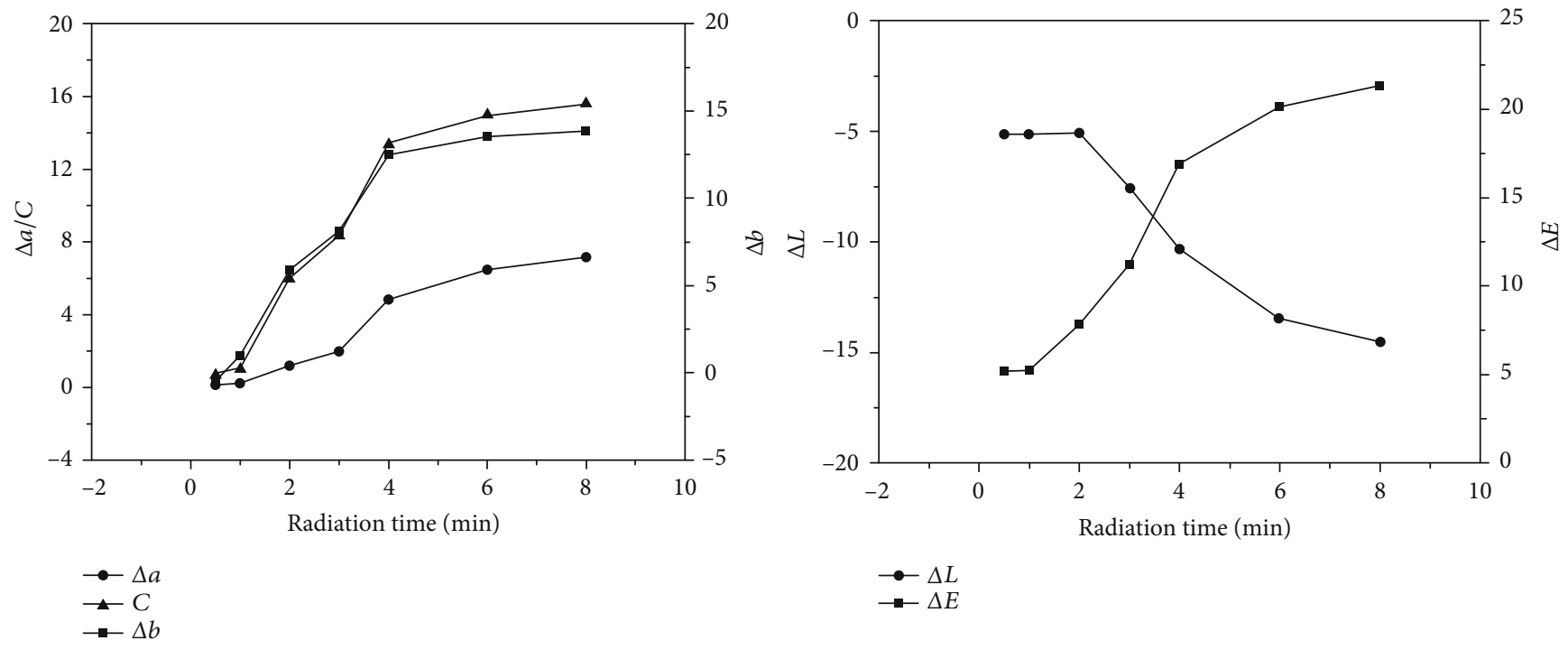

Figure 4: Effects of radiation time on $\Delta E, \Delta L, \Delta a, \Delta b$, and $C$ of bamboo (from left to right: $0.5,1,2,3,4,6$, and 8 min).

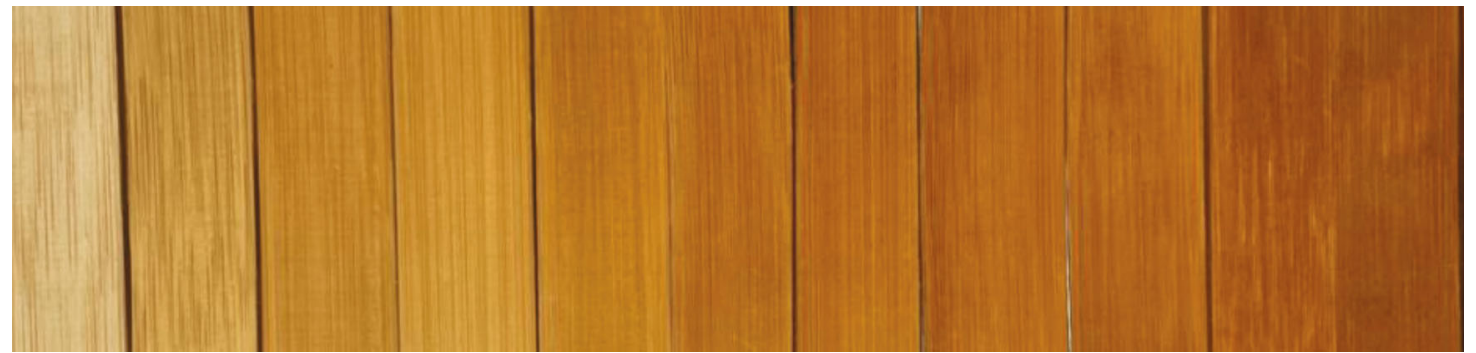

FIGURE 5: Effects of long-time UV radiation on bamboo color ( $10 \mathrm{~cm}$, from left to right: control and $0.5,1,2,4,6,8,10,12,16$, and $20 \mathrm{~h})$.

high-pressure mercury light, the reflection curve of bamboo decreased apparently from $360 \mathrm{~nm}$ (Figure $7(\mathrm{a})$ ), indicating that more visible light was absorbed by bamboo. The $K-M$ curves of UV-radiated bamboo (Figure 7(b)) also increased significantly, especially in the range of $400-425 \mathrm{~nm}$. The $K$ - $M$ absorption at $410 \mathrm{~nm}$ is reportedly caused by the products of lignin degradation [3].

\subsection{Effect of Thermal Treatment on UV-Radiated Bamboo} Color. Three thermal treatments popularly used in the bamboo industry were adopted to change bamboo color before UV radiation. The groups from Figures $8(\mathrm{a})-8(\mathrm{c})$ are the untreated bamboo, hot water treatment $\left(\mathrm{HW}, 80^{\circ} \mathrm{C}, 2 \mathrm{~h}\right)$, high-temperature air heat treatment (HTA: $\left.180^{\circ} \mathrm{C}, 2 \mathrm{~h}\right)$, and saturated steam heat treatment (SS: $0.39 \mathrm{MPa}, 2 \mathrm{~h}$ ), respectively, were performed under radiation by UV 313 at a distance of $10 \mathrm{~cm}$ from bamboo specimens. After thermal treatments, the bamboo surface turned dark, especially in SS specimens, which turned brown (Figure 8(a)). After SS treatment, high contents of phenol and organic acids, especially acetic acid, were produced, which were mainly degraded from hemicellulose and extracts [11]. The gradated products greatly influenced the bamboo color. The heated bamboo specimens in Figure 4 can be separated as lightcolored specimens (control, HW, and HTA) and darkcolored specimens (SS). After UV radiation, light-colored specimens turned dark and dark-colored specimens became lighter. For all of the specimens, color faded at 28 days. 

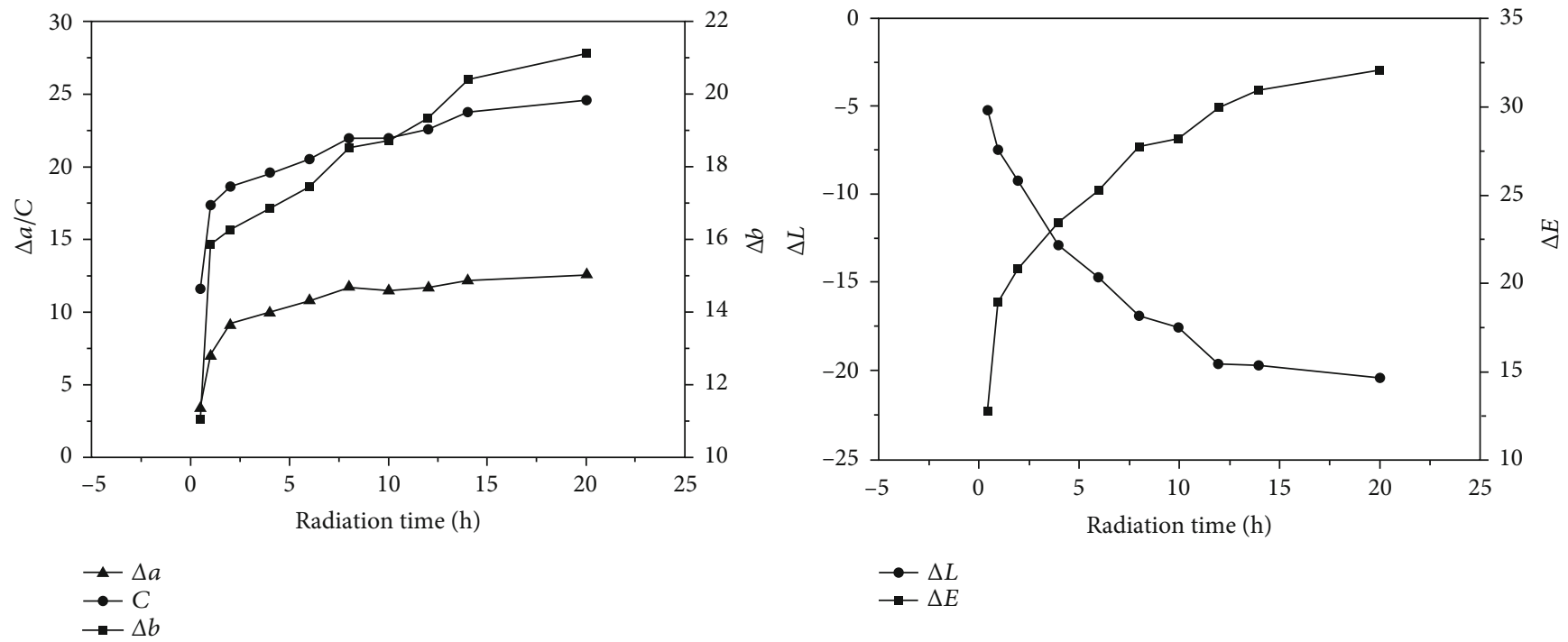

Figure 6: Effects of long-time UV radiation on $\Delta E, C, \Delta L, \Delta a$, and $\Delta b$ of bamboo ( $10 \mathrm{~cm}$, from left to right: $0.5,1,2,4,6,8,10,12,14$, and $20 \mathrm{~h})$.

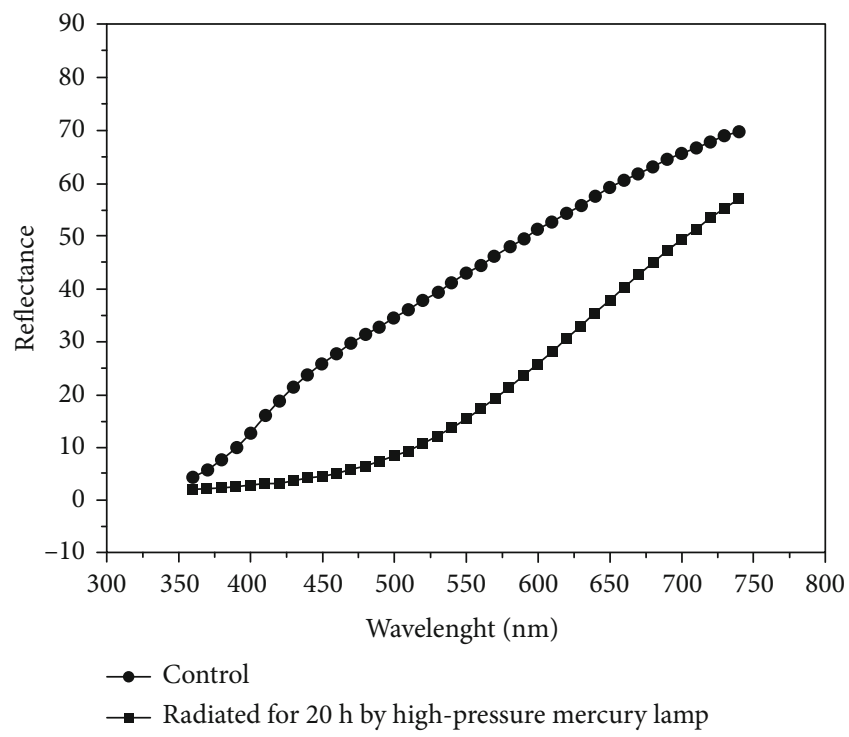

(a)

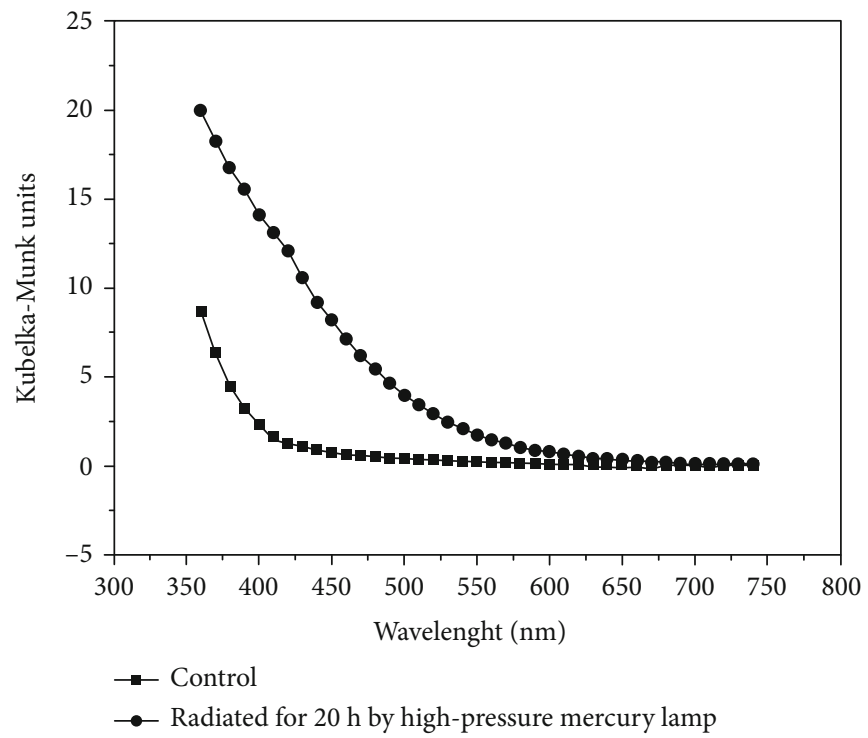

(b)

FIGURE 7: Reflectance spectra (a) and $K-M$ spectra (b) of UV-radiated bamboo.

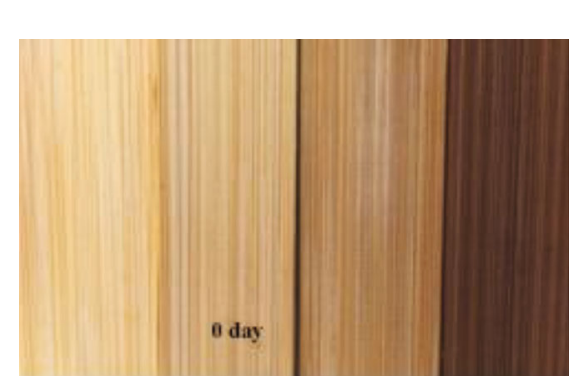

(a)

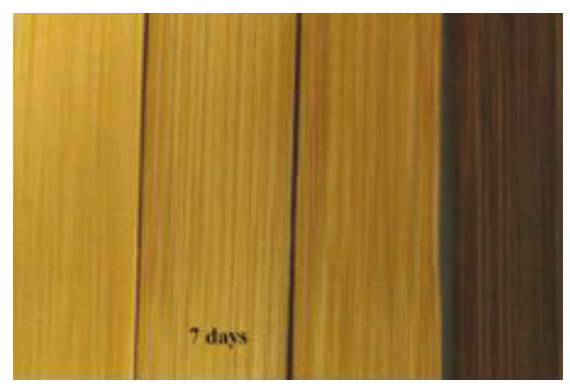

(b)

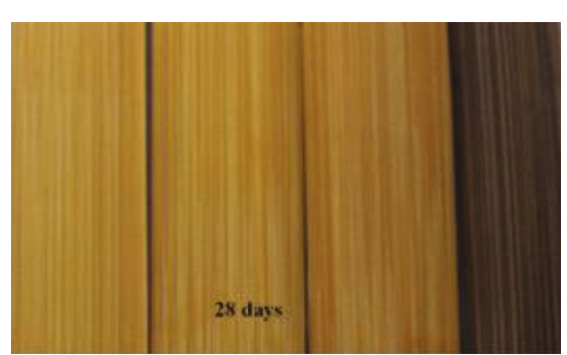

(c)

FIGURE 8: Effect of heat treatment on bamboo photodiscoloration: (a) control, (b) $7 \mathrm{~d}$, and (c) $28 \mathrm{~d}$. 

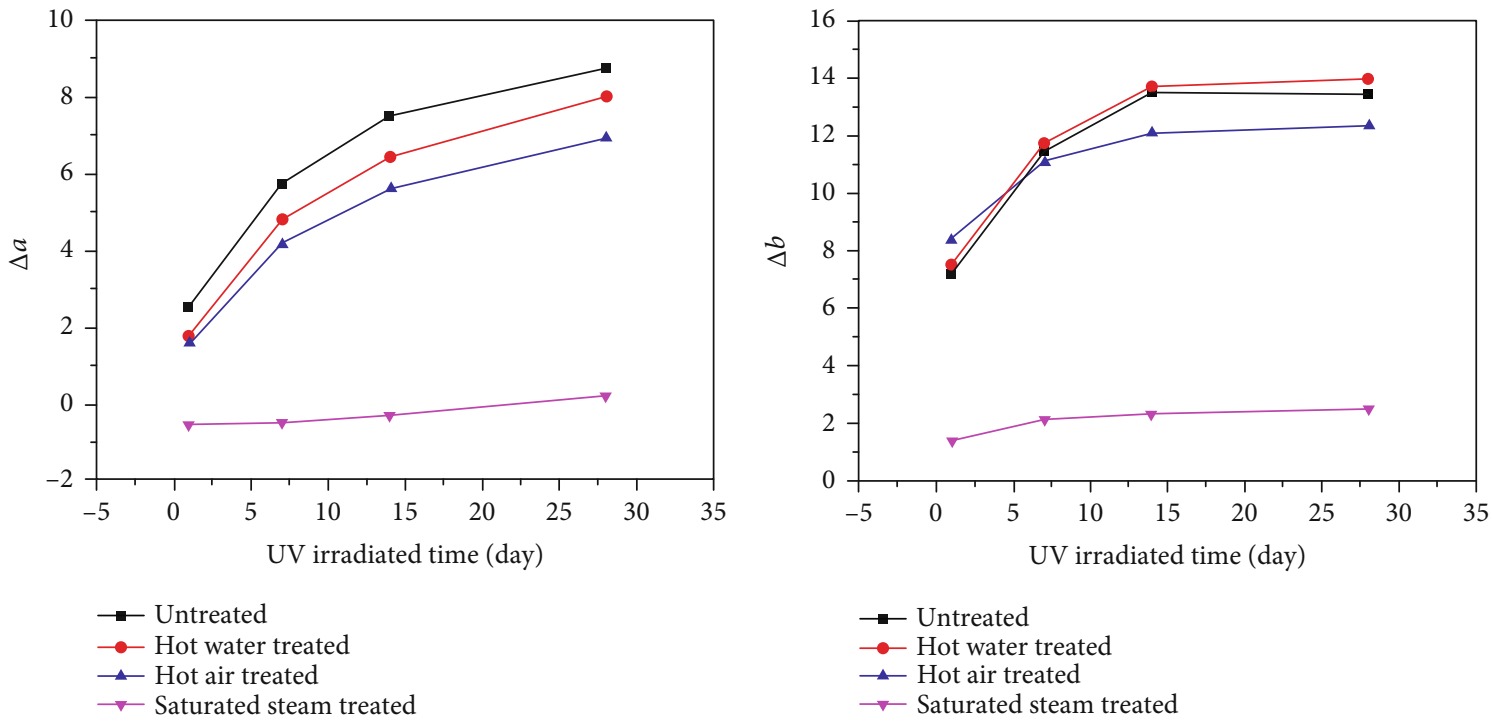

(a)

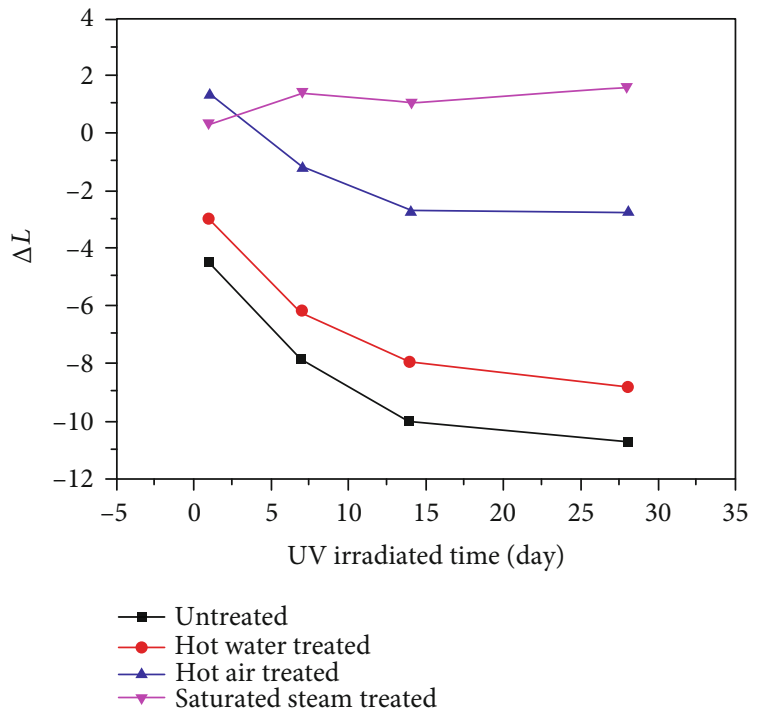

(c)

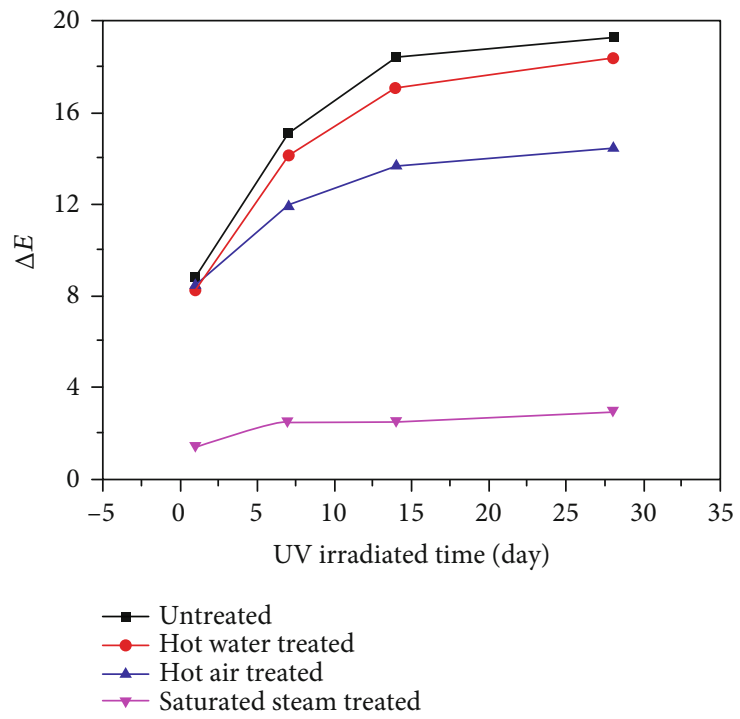

(d)

FIGURE 9: Effect of heat treatment on $\Delta E, \Delta a, \Delta b$, and $\Delta L$ of UV 313-irradiated bamboo: (a) control, (b) $7 \mathrm{~d}$, (c) $14 \mathrm{~d}$, and (d) $28 \mathrm{~d}$.

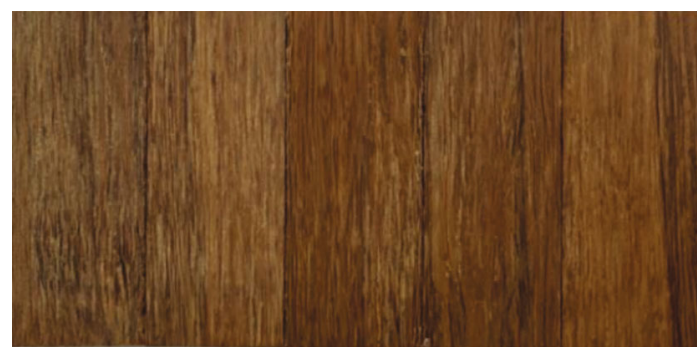

(a)

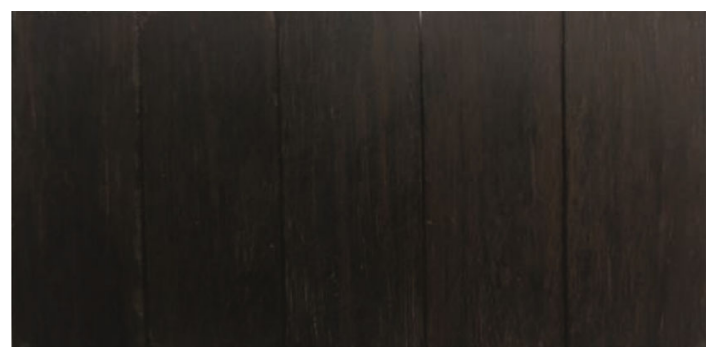

(b)

FIGURE 10: Effect of UV radiation time on light (a) and dark (b) carbonized bamboo scrimbers.

Lignin and extracts are the main chromogenic groups of bamboo materials. During heat treatment, lignin was polymerized to some extent [5] and extracts were modified [12]. Color parameters of thermally treated bamboo specimens all changed less than the control specimens after UV radiation, and the higher temperature treatment led to more stable color (Figure 9). The redness and yellowness of SS-treated specimens hardly changed during UV radiation, which 


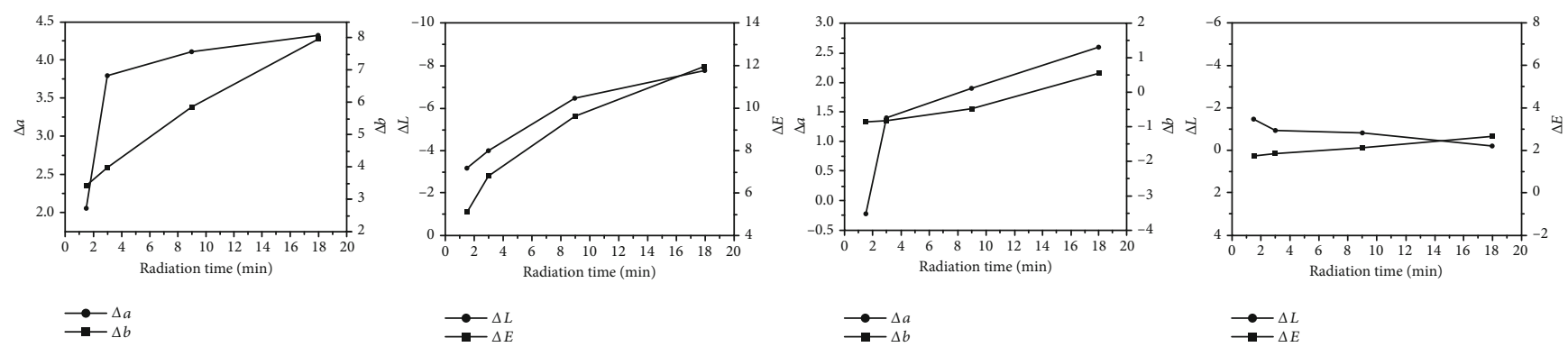

FigURE 11: Effect of UV radiation on bamboo scrimbers (from left to right: $\Delta a$ and $\Delta b$ and $\Delta E$ and $\Delta L$ for light carbonized; $\Delta a$ and $\Delta b$ and $\Delta E$ and $\Delta L$ for dark carbonized).

TABLe 1: The main degraded products identified by GC-MS from UV-aged Moso bamboo.

\begin{tabular}{|c|c|c|c|c|c|}
\hline No. & CAS & Molecular formula & English name & Group area & Structural formula \\
\hline 1 & $123-08-0$ & $\mathrm{C}_{7} \mathrm{H}_{6} \mathrm{O}_{2}$ & p-Hydroxybenzaldehyde & $4,922,530.60$ & \\
\hline 2 & $621-59-0$ & $\mathrm{C}_{8} \mathrm{H}_{8} \mathrm{O}_{3}$ & Isovanillin & $6,593,258.99$ & \\
\hline 3 & $99-93-4$ & $\mathrm{C}_{8} \mathrm{H}_{8} \mathrm{O}_{2}$ & $4^{\prime}$-Hydroxyacetophenone & $1,547,854.13$ & \\
\hline 4 & $498-02-2$ & $\mathrm{C}_{9} \mathrm{H}_{10} \mathrm{O}_{3}$ & $4^{\prime}$-Hydroxy-3'-methoxyacetophenone & $2,313,156.21$ & \\
\hline 5 & $645-08-9$ & $\mathrm{C}_{8} \mathrm{H}_{8} \mathrm{O}_{4}$ & 3-Hydroxy-4-methoxybenzoic acid & $3,395,412.37$ & \\
\hline 6 & $98-29-3$ & $\mathrm{C}_{10} \mathrm{H}_{14} \mathrm{O}_{2}$ & 4-tert-Butylcatechol & $2,177,054.12$ & \\
\hline 7 & $1132-21-4$ & $\mathrm{C}_{9} \mathrm{H}_{10} \mathrm{O}_{4}$ & 3,5-Dimethoxybenzoic acid & $1,371,235.46$ & \\
\hline 8 & $134-96-3$ & $\mathrm{C}_{9} \mathrm{H}_{10} \mathrm{O}_{4}$ & Syringaldehyde & $6,275,856.42$ & \\
\hline 9 & $2478-38-8$ & $\mathrm{C}_{10} \mathrm{H}_{12} \mathrm{O}_{4}$ & Acetosyringone & $2,351,205.43$ & \\
\hline 10 & $530-57-4$ & $\mathrm{C}_{9} \mathrm{H}_{10} \mathrm{O}_{5}$ & Syringic acid & $3,341,287.46$ & \\
\hline 11 & $2196-18-1$ & $\mathrm{C}_{10} \mathrm{H}_{12} \mathrm{O}_{4}$ & $\beta$-Hydroxypropiovanillone & $6,170,213.55$ & \\
\hline 12 & $39151-19-4$ & $\mathrm{C}_{10} \mathrm{H}_{12} \mathrm{O}_{3}$ & $3^{\prime}, 5^{\prime}$-Dimethoxyacetophenone & $144,588.51$ & \\
\hline
\end{tabular}

proves the photostability of the high-temperature-modified bamboo.

Figure 9 shows that color parameter changes were slowed down with time and almost maximized and stabilized at 28 days. The maximum color changes $(\Delta a, \Delta b, \Delta L$, and $\Delta E)$ radiated by UV 313 were all less than those of 8 -minute radiation by the high-pressure mercury light. Consequently, the high-pressure mercury lamp light was highly efficient and took less time to induce discoloration.

After thermal treatments, $\Delta a, \Delta b$, and $\Delta E$ increased and $\Delta L$ decreased, while surface color became darker (Figure 9). Reportedly, thermal treating can protect and slow down the photoaging to a certain extent [13], but this is inapplicable for high-temperature treatment, such as SS-treated bamboo; 
TABLE 2: The main degraded products identified by HPLC-MS from UV-aged Moso bamboo.

\begin{tabular}{|c|c|c|c|c|c|}
\hline No. & CAS & Molecular formula & English name & Group area & Structural formula \\
\hline 1 & $8027-56-3$ & $\mathrm{C}_{6} \mathrm{H}_{12} \mathrm{O}_{6}$ & p-Hydroxybenzaldehyde & $21,531,976.80$ & \\
\hline 2 & $14641-93-1$ & $\mathrm{C}_{12} \mathrm{H}_{22} \mathrm{O}_{11}$ & Isovanillin & $34,717,194.87$ & \\
\hline 3 & $6915-15-7$ & $\mathrm{C}_{4} \mathrm{H}_{6} \mathrm{O}_{5}$ & $4^{\prime}$-Hydroxyacetophenone & $378,427,506.25$ & \\
\hline 4 & $527-61-7$ & $\mathrm{C}_{8} \mathrm{H}_{8} \mathrm{O}_{2}$ & 2,6-Dimethylbenzoquinone & $286,856,553.02$ & \\
\hline 5 & $99-96-7$ & $\mathrm{C}_{7} \mathrm{H}_{6} \mathrm{O}_{3}$ & 3-Hydroxy-4-methoxybenzoic acid & $188,840,834.29$ & \\
\hline 6 & $331-39-5$ & $\mathrm{C}_{9} \mathrm{H}_{8} \mathrm{O}_{4}$ & 4-tert-Butylcatechol & $2,199,219.54$ & \\
\hline 7 & $2107-77-9$ & $\mathrm{C}_{10} \mathrm{H}_{8} \mathrm{O}_{4}$ & 3,5-Dimethoxybenzoic acid & $23,782,373.13$ & \\
\hline 8 & $121-33-5$ & $\mathrm{C}_{8} \mathrm{H}_{8} \mathrm{O}_{3}$ & Syringaldehyde & $454,084,233.89$ & \\
\hline 9 & $103-26-4$ & $\mathrm{C}_{10} \mathrm{H}_{10} \mathrm{O}_{2}$ & Acetosyringone & $4,216,017.43$ & \\
\hline 10 & $480-19-3$ & $\mathrm{C}_{16} \mathrm{H}_{12} \mathrm{O}_{7}$ & Syringic acid & $31,272,952.29$ & \\
\hline
\end{tabular}

surface color of which was totally changed by high temperature. This conclusion is in accordance with the results from Nemeth et al. [12] that lignin was polymerized under high temperature and was pivotal in preventing free radical reaction during photoaging. It can be deduced that extracts contribute more to redness and lignin contributes more to yellowness (new carbonyl formation).

\subsection{Effect of UV Radiation on Surface Color of Bamboo} Scrimbers. Figure 10 shows visual appearance of bamboo scrimbers after high-pressure mercury light radiation. The groups from left to right are control and radiation for 1.5, 3,9 , and $18 \mathrm{~min}$, respectively, and the distance from each specimen to the light source was set as $10 \mathrm{~cm}$. Compared with bamboo specimens, color changes of bamboo scrimbers were less and slower (Figure 11 from changes of $\Delta E$, $\Delta L, \Delta a$, and $\Delta b$ ), which may be attributed to high density and heat treatment [14]. Both light and dark carbonated bamboo scrimbers showed discoloration at $9 \mathrm{~min}$, but the light specimens became increasingly dark and the dark specimens faded.

The color parameters of dark carbonized scrimbers changed less than those of light carbonized scrimbers (Figure 11), indicating that high-temperature-treated bamboo showed color stability under UV radiation.
3.6. Bamboo Surface Chemical Changes after UV Radiation by GC-MS. The photodegraded bamboo layer (radiated by highpressure mercury lamp at $10 \mathrm{~cm}$ distance for $20 \mathrm{~h}$ ) was obtained and extracted by ethyl acetate. High contents of isovanillin, syringaldehyde, $\beta$-hydroxypropiovanillone, $\mathrm{p}$ hydroxybenzaldehyde, and syringic acid were identified by GC-MS (Table 1). These products mainly resulted from the breakdown of lignin macromolecules or aromatic extracts, as proven by Mattonai [15] who detected large amounts of carbonyl and phenolic compounds in lignin degradation by UV light by escape gas analysis mass spectrometry. The degraded products contained conjugated double bonds with benzene rings.

Enrichment of products containing conjugated double bonds on the bamboo surface changed spectral absorbing characteristics and shifted surface color from visible to the UV region, leading to discoloration [16]. The photodegraded products then covered the surface and prevented the layer beneath from degradation. However, most of the degraded products were water-soluble and easily washed away by rain [17] or wind, leaving the cellulose-rich greyish white.

3.7. Bamboo Surface Chemical Changes after UV Radiation by HPLC-MS. The photodegraded bamboo layer (radiated by high-pressure mercury lamp at $10 \mathrm{~cm}$ distance for $20 \mathrm{~h}$ ) was 


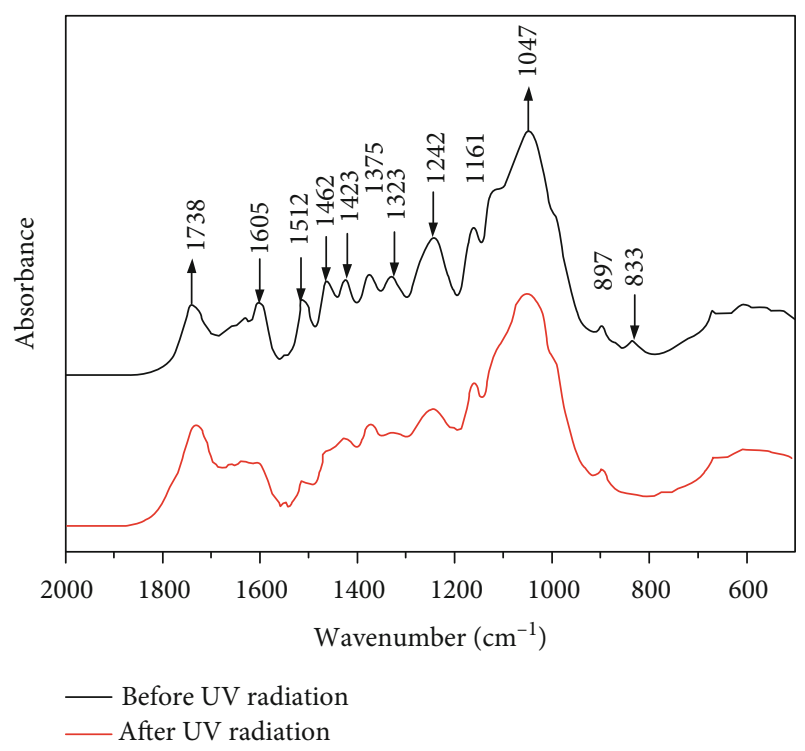

FIGURE 12: FTIR of UV 313-radiated bamboo.

obtained and extracted by acetonitrile. The main degraded products detected by HPLC-MS are presented in Table 2 according to the peak time. Relative high contents of 3hydroxy-4-methoxybenzoic acid, 2,6-dimethylbenzoquinone, and syringaldehyde were identified by HPLC-MS (Table 2), which are all rich in the conjugated double bond (chromogenic group). The 2,6-dimethylbenzoquinone has a cyclohexenedione structure and highly conjugated structures, which are quite different from other types of benzene ring-containing products. Conjugated structures in 2,6dimethylbenzoquinone were more stable than those conjugated double bonds with benzene rings and were supposed to be the final products during bamboo photodegradation that played an important role in bamboo photodiscoloration.

3.8. Bamboo Surface Analysis by FTIR. After UV 313 radiation, peaks at 1605,1512,1462,1423,1323, 1242, and $833 \mathrm{~cm}^{-1}$ that represent lignin aromatic absorption decreased and peaks at $1605,1512,1462$, and $833 \mathrm{~cm}^{-1}$ almost disappeared (Figure 12). By contrast, the peaks at 1047 and $1738 \mathrm{~cm}^{-1}$ which represent unconjugated carbonyl $\mathrm{C}=\mathrm{O}$ stretching vibration of acetyl groups enhanced. These results indicate the formation of new unconjugated carbonyl groups [18]. Reportedly, yellow change is attributed to the formation of new carbonyl groups [19]. Absorption peaks representing polysaccharide at 1375,1161 , and $897 \mathrm{~cm}^{-1}$ remained nearly unchanged during radiation, suggesting that cellulose and hemicellulose changed little during the process.

\section{Conclusions}

UV light initiated photodegradation and photodiscoloration on the bamboo surface. For both UV 313 and high-pressure mercury light, color changed rapidly at first and then stabilized for long time. Compared with UV 313, high-pressure mercury lamp light was highly efficient and took less time to induce discoloration. For both light sources, light- colored bamboo became dark and dark-colored bamboo turned light. Surface color changes of bamboo scrimbers were less and slower than those of bamboo, which was ascribed to high density and heat treatment. Extracts contributed more to redness, and lignin contributed more to yellowness during photodiscoloration. Dark carbonized scrimber changed less than light carbonized scrimber did. During high-temperature treatment, lignin was polymerized and extracts were modified, and bamboo was highly photostable. Color of the saturated stream-treated bamboo in the experiment hardly changed during UV radiation. Most of the degraded products identified by GC-MS and HPLC-MS contained conjugated double bonds and were conjectured to be degraded from lignin or aromatic extracts, among which 2,6-dimethylbenzoquinone was most stable and was supposed to be the final photodegrad product. FTIR suggests the formation of new unconjugated carbonyl and little change of cellulose and hemicellulose.

Bamboo photodiscoloration is simple and can be controlled by light sources, radiation time, and distance and may be used for bamboo dyeing. New chromogenic groups can enrich bamboo color, but they are unstable and can be easily oxidized and washed away by wind or water. In our ongoing research, a light inducer will be added to induce directional discoloration, and color stabilizing treatment will be tried.

\section{Data Availability}

The data used to support the findings of this study are available from the corresponding author upon request.

\section{Conflicts of Interest}

The authors declare that they have no conflicts of interest.

\section{Acknowledgments}

The work was supported by Zhejiang Forestry Administration (grant number 2021SY06) and Science Technology Department of Zhejiang Province (grant number 2019F1065).

\section{References}

[1] L. Tolvaj and K. Mitsui, "Light source dependence of the photodegradation of wood," Journal of Wood Science, vol. 51, no. 5, pp. 468-473, 2005.

[2] Y. J. Xu, "Wood color and wood color treatment," vol. 1, Forestry science and technology development, China, 1996.

[3] T. C. M. Pastore, K. O. Santos, and J. C. Rubim, "A spectrocolorimetric study on the effect of ultraviolet irradiation of four tropical hardwoods," Bioresource Technology, vol. 93, no. 1, pp. 37-42, 2004.

[4] D. N. S. Hon and G. Ifju, "Measuring penetration of light into wood by detection of photo-induced free radicals," Wood Science, vol. 11, no. 2, pp. 118-127, 1978.

[5] X. A. Huang, D. Kocaefe, Y. Kocaefe, Y. Boluk, and A. Pichette, "A spectrocolorimetric and chemical study on color modification of heat-treated wood during artificial weathering," Applied Surface Science, vol. 258, no. 14, pp. 5360-5369, 2012. 
[6] T. Kanbayashi, Y. Kataoka, A. Ishikawa, M. Matsunaga, M. Kobayashi, and M. Kiguchi, "Confocal Raman microscopy reveals changes in chemical composition of wood surfaces exposed to artificial weathering," Journal of Photochemistry and Photobiology B, vol. 187, pp. 136-140, 2018.

[7] P. Peng, F. Peng, J. Bian, F. Xu, and R. C. Sun, “A comparative study of bamboo (Phyllostachys incarnata Wen) milled wood lignin and the successively alkali-fractionated lignins," Wood Science and Technology, vol. 46, no. 5, pp. 871-885, 2012.

[8] N. X. Jiang, Z. M. Liu, H. Q. Ren, S. Y. Han, and C. Y. Zhu, "Changes of phenolic acids and total phenolic acids contents in cell walls of Moso bamboos at different ages," Journal of Bamboo Research, vol. 29, no. 1, pp. 24-28, 2010.

[9] R. A. Zabel and J. J. Morrell, "Wood microbiology (second edition) decay and its prevention," Chapter Two-Wood deterioration agents, pp. 19-54, 2020.

[10] Y. R. Hou, S. N. Yan, G. Huang, Q. P. Yang, S. R. Huang, and J. J. Cai, "Fabrication of N-doped carbons from waste bamboo shoot shell with high removal efficiency of organic dyes from water," Bioresource Technology, vol. 303, article 122939, 2020.

[11] Y. Mori, Y. Kuwano, S. Tomokiyo, N. Kuroyanagi, and K. Odahara, "Inhibitory effects of Moso bamboo (Phyllostachys heterocycla $\mathrm{f}$. pubescens) extracts on phytopathogenic bacterial and fungal growth," Wood Science and Technology, vol. 53, no. 1, pp. 135-150, 2019.

[12] R. Nemeth, L. Tolvaj, M. Bak, and T. Alpar, "Colour stability of oil-heat treated black locust and poplar wood during shortterm UV radiation," Journal of Photochemistry and Photobiology A: Chemistry, vol. 329, pp. 287-292, 2016.

[13] X. A. Huang, D. Kocaefe, Y. Kocaefe, Y. Boluk, and A. Pichette, "Study of the degradation behavior of heat-treated jack pine (Pinus banksiana) under artificial sunlight irradiation," Polymer Degradation and Stability, vol. 97, pp. 1197-1214, 2012.

[14] Y. X. Huang, Y. H. Ji, and W. J. Yu, "Development of bamboo scrimber: a literature review," Journal of Wood Science, vol. 65, no. 1, p. 25, 2019.

[15] M. Mattonai, "Degradation of wood by UV light: a study by EGA-MS and Py-GC/MS with on line irradiation system," Journal of Analytical and Applied Pyrolysis, vol. 139, pp. 224232, 2019.

[16] H. X. Yu, X. Pan, M. P. Xu, W. M. Yang, J. Wang, and X. W. Zhuang, "Surface chemical changes analysis of UV-light irradiated Moso bamboo (Phyllostachys pubescens Mazel)," Royal Society open science, vol. 78, no. 6, article 180110, 2018.

[17] L. Bejo, L. Tolvaj, A. Kannar, and E. Preklet, "Effect of water leaching on photodegraded spruce wood monitored by IR spectroscopy," Journal of Photochemistry and Photobiology A: Chemistry, vol. 382, article 111948, 2019.

[18] X. Q. Wang and H. Q. Ren, "FTIR and XPS spectroscopic studies of photodegradation of Moso bamboo (Phyllostachys pubescens Mazel)," Spectro Scopy and Spectral Analysis, vol. 29, no. 7, pp. 1864-1867, 2009.

[19] B. M. Esteves, A. V. Marques, I. J. Domingos, and H. Pereira, "Influence of steam heating on the properties of pine (Pinus pinaster) and eucalypt (Eucalyptus globulus) wood," Wood Science and Technology, vol. 41, no. 3, pp. 193-207, 2007. 